\title{
Enkele gedagtes oor Matteus se gebruikmaking van die Ou Testament in Matteus 2:15
}

\author{
AB du Toit
}

\begin{abstract}
Some thoughts on Matthew's usage of the Old Testament in Matthew 2:15
\end{abstract}

To make general statements on Old Testament quotations in the New is extremely hazardous. Therefore one citation only is pinpointed. The micro-context of Matthew's citation of Hosea 11:1 shows that a very close relationship between Jesus and Israel is established and that the sojourn in Egypt is doubly divinely sanctioned. An analysis of the quotation within the wider gospel context not only confirms this but also shows that Matthew uses it in a very sophisticated way. He intends 'theologizing' Jesus' childhood movements, showing them to be part of God's plan for his Messiah. This may also have an apologetic undertone. The quotation is in another sense christologically important: It forms part of a chain of Christological pronouncements. Jesus' identity can, however, only be revealed by God himself. We cannot endorse Matthew's usage of the Old Testament quotation in Hosea 11:1, but we can appreciate how he came to his understanding of it. His association of Jesus with Israel must have played a major role. More information on the Wirkungsgeschichte of this text in Early Judaism would probably have furthered our understanding.

\section{INLEIDEND}

Wie hom aan die Ou-Testamentiese sitate in die Nuwe Testament waag, moet goed weet wat hy doen. Hy moet besef dat hy een van die moeilikste probleemvelde in die Nuwe Testament betree en dat hy kwalik sonder letsels uit die stryd sal tree. Afhangende van sy bevindings sal hy bloedneus opdoen, of van fundamentalistiese kant of van kritiese kant. En as hy 'n versigtige middeweg probeer bewandel, kry hy dit, as beloning vir sy moeite, straks van albei.

Een van die akute gevare by ' $n$ bespreking van die Ou-Testamentiese aanhalings in die Nuwe Testament is - soos in soveel ander gevalle dié van veralgemening. Nuwe-Testamentiese outeurs benut die $\mathrm{Ou}$ Testament immers geensins op 'n eenvormige manier nie. Om hierdie 
rede is dit goed dat op 'n heel spesifieke uitspraak in 'n heel spesifieke evangelie gekonsentreer word, naamlik dié in Matteus 2:15. Hierdie gedeelte lui soos volg:

kaì èn ekeĩ héōs tēs teleutēs Hêrốdou hína plèrōthē tò rhēthèn hupò kuriou dià toũ profétou légontos

ex Aigúptou ekálesa tòn huión mou (Hos 11:1)

Kom ons formuleer onmiddellik ons probleemstelling in verband mat hierdie sitaat uit Hosea 11:1: Ons probleem bestaan daarin dat die onbevange leser uit Matteus sonder meer die indruk kry dat die evangelis hier 'n uitspraak wat in Hosea 11:1 op Israel dui en wat 'deur terug te gryp na die uittog uit Egipte beklemtoon dat Israel se enigste bestaansgrond geleë is in die liefde van en uitverkiesing deur Jahwe' (Prinsloo 1986 se formulering), hanteer asof dit in werklikheid met die oog op Jesus Christus, die komende Messiaskoning, se Egipteverblyf geskryf was en daarin sy daadwerklike vervulling gevind het. Hierdie is geen resente probleem nie. Reeds Calvyn het byvoorbeeld hiermee in verleentheid gesit, soos blyk uit sy poging om dit te omseil (kyk Tholuck 1838: $80 \mathrm{v}$ ).

Om hierdie probleem in perspektief te sien gaan ons eerstens aandag gee aan die sitaat in Matteus 2:15 binne sy onmiddellike konteks en daarna binne sy makrokonteks.

\section{DIE SITAAT IN MATTEUS 2:15 BINNE SY ONMIDDELLIKE KONTEKS}

Ons sitaat vorm die afsluiting en hoogtepunt van Matteus 2:13-16. Hierdie perikoop vorm 'n episode in Matteus se Jesusverhaal, waarby veral 2:19-23 baie nou aansluit. Dit gaan hier om 'n goddelike aanwysing (vs 13) deur middel van 'n droom dat Josef met die Kindjie en sy moeder (let op die volgorde: tò paídion staan voorop, want bo alles gaan dit om Hom) na Egipte moet vlug en daar moet vertoef totdat hy opdrag van God ontvang om terug te keer. Die naam 'Egipte' sou in die gemoed van elke 'Bybelvaste' leser van Matteus spesifieke assosiasies opgeroep het. Daar was 'n hele tradisie in Israel van vlug na Egipte in krisistye (vgl 1 Kon 11:40; Jer 26:21-23; 41 vv; kyk veral Gundry 1982: 33). Maar die allesoorheersende assosiasie was uiteraard Israel se verblyf in Egipte. Dat Matteus in sy aanbieding 'n duidelike verband tussen Israel en Jesus se verblyf in Egipte plaas, word algemeen deur kommentatore aanvaar (o.a. Pesch 1967: 412; Grundmann 1968: 85 v; 
Gundry 1982: 34; Luz 1985: 129). Selfs indien 'n mens sou twyfel of die evangelis ' $n$ duidelike verband tussen Herodes en Farao se kindermoorde trek, val die duidelike toespeling op Eksodus 4:19-20 in vers 20 nie te ontken nie. Daar is ' $n$ lotsverbondenheid tussen Israel en sy Verlosserkoning, sy Immanuel. Hulle lot is sy lot. Om hulle te kan verlos, vereenselwig $\mathrm{Hy}$ Hom volledig met die geskiedenis van die volk Israel. ${ }^{*}$ Juis so is Hy nie alleen die ware Koning van die Jode (vgl 2:2,6) nie, maar ook hulle Immanuel (1:23), die Jesus wat sy volk van hulle sondes sal verlos $(1: 21){ }^{* *}$

Dit is duidelik dat dit in die aanhaling van 2:15 om Jesus Christus en sy roeping uit Egipte gaan. Die hína in die inleiding dui duidelik doel aan. Die werkwoord plèróō in die aoristus subjunktief ná hína dui hier, soos so dikwels elders by Matteus, op die eskatologiese vervulling van die ou bedeling in die koms van Jesus Christus (vgl Luz 1985: $48 \mathrm{v}$ vir plèróō as voorkeurwoord by Matteus). Dit is opmerklik dat Jesus se Egipteverblyf dubbel deur God gesanksioneer word. Eerstens vind daar 'n direkte openbaring in 'n droom aan Josef plaas (vs 13) en tweedens bekragtig die aanhaling dat hierdie Egipteverblyf reeds in die Ou Testament as deel van God se toekomsplan vir sy Messias vasgelê is. Die Egipteverblyf word dus omraam met God se doelgerigte beheer oor die weg van Israel se Messiaskoning. Dit is God se plan, sy heilsplan, wat hier aan die orde is en Jesus volg hierdie plan, via Josef sy juridiese vader, haarfyn. Ook Egipte is in hierdie plan ingesluit.

Nog ' $n$ ander saak is in die aanhaling belangrik: Dit is die Kurios, in hierdie geval Jahwe self, wat hier aan die woord gestel word en Hy noem hierdie Kindjie 'my seun'. Ons het hier 'n uiters belangrike Christologiese uitspraak. Afgesien van die verwysing na Jesus as Koning van die Jode en as leierherder (vs 6), is hierdie die enigste Christologiese benaming in hierdie hoofstuk en in elk geval die heel belangrikste.

* Algemeen word ook aanvaar dat ons naas die Israel-Jesus verbandlegging in hierdie gedeelte ook 'n parallel vind tussen Jesus Christus en Moses. Eersgenoemde is die Moses-redivivus, die tweede Moses. Hierdie visie is besonder duidelik in die aanloop tot die Bergrede waar Jesus, soos Moses, op die berg klim en nou die 'Wet van die Messiaskoning' aan die nuwe Godsvolk voorhou.

* Vir die belang van die Immanuel-Christologie vir Matteus vgl Combrink (1985: 81, 91). Hierdie motief is nog sterker uitgewerk deur Van Aarde (1982) in sy doktorale proefskrif. Daar bestaan egter nog steeds 'n behoefte dat die Christologie van Matteus (insluitende die Christologiese titels) sterker geïntegreer word. Motiewe soos Immanuel, Seun van God, Kurios, Messiaskoning, Seun van Dawid moet as deel van 'n geintegreerde visie hanteer word. Vgl veral die belangrike opmerkings by Van Aarde (1982: 64-66). 
Die belang van feitlik al die reedsgenoemde gesigspunte sal nou verder blyk wanneer ons ons aanhaling binne die ruimer konteks van Matteus 1-2 en die makrokonteks van die evangelie as geheel plaas.

\section{DIE AANHALING IN MATTEUS 2:15 BINNE SY MAKROKONTEKS}

Ons aanhaling is een van die elf sogenaamde vervullingsitate (1:22 v; $2: 15,17 \mathrm{v} ; 23 ; 4: 14-16 ; 8: 17 ; 12: 17-21 ; 13: 35 ; 21: 4 \mathrm{v} ; 26: 56$ en $27: 9$ ) wat so 'n belangrike plek in Matteus inneem.* Dit sou egter verkeerd wees om hierdie sitate as ' $n$ heel unieke kategorie by Matteus te beskou. Daar bestaan by hom nie werklik so 'n andersoortigheid tussen die vervullingsitate en die ander sitate en toespelings op die Ou Testament (Luz 1985: 134) nie. Tog is dit so dat hierdie sitate vanweë hulle uitgebreide inleidings en ook vanweë hulle inhoud by Matteus ' $n$ besondere gewig kry.

Afgesien van geringe afwykings vertoon hierdie aanhalings 'n vaste patroon:

\begin{tabular}{|c|c|c|}
\hline $\begin{array}{l}\text { toûto dè (hólon) } \\
\text { gègonen }(3 \mathrm{x}) \text { of } \\
\text { tóte }(2 \mathrm{x}) \text { of niks } \\
(6 \mathrm{x})\end{array}$ & $\begin{array}{l}\text { hina/hópōs } \\
\text { (behalwe in die } \\
\text { twee gevalle } \\
\text { waar tóte } \\
\text { gebruik word) }\end{array}$ & $\begin{array}{l}\text { plèrōthē } \\
\text { (maar saam } \\
\text { met tóte: } \\
\text { eplèrōthē) }\end{array}$ \\
\hline
\end{tabular}

$\begin{array}{lll}\text { dià tô̂ profétou } & \text { légontos } & \text { sitaat } \\ \text { (of variante; } & \text { (slegs } 2 \times \text { nie) }\end{array}$

$2 x$ deur hupò

kuriou vooraf-

gegaan).

Dit sou egter ' $n$ totale mistasting wees om te meen dat Matteus hierdie sitate op ' $n$ vry ondeurdagte of ongenuanseerde wyse aanbied. Die evangelis wend sy aanhalings in werklikheid heel gesofistikeerd binne die voortgang van sy Jesusverhaal aan.

Hierdie feit blyk alreeds uit die konsentrasie van vervullingsitate aan

* Duitse geleerdes praat ook van Reflexionszitate. In die Engelse teologie is die benaming formula quotations. Oor die identifikasie en die getal van die vervullingsitate bestaan verskil. Combrink (1985: 82) voeg Matteus $2: 6$ by en kom so by 12 uit. Rotfuchs (1969: $22 \mathrm{vv}$ ) voeg ook $2: 6$ by, maar vervang $26: 56$ met $26: 31$. Wanneer ons die tegniese term 'vervullingsitate' gebruik, is dit myns insiens raadsaam om slegs daardie gedeeltes in te sluit waar die werkwoord plēróō spesifiek voorkom. Tereg noem Luz (1985: 135 2:5 v) en sekere ander aanhalings egter 'byna-vervullingsitate'. 
die begin van die evangelie. In die eerste twee hoofstukke (soms ook genoem die proloog van Matteus) verskyn nie minder as vier van die elf vervullingsitate nie. Dit is geensins toevallig nie. Hier heel aan die begin van sy aanbieding wil die evangelis deur middel van ' $n$ ophoping van inhoudelik veelseggende vervullingsitate sy lesers 'kondisioneer' om die res van sy evangelieverhaal vanuit ' $n$ heel bepaalde perspektief te begryp. Hy wil hulle 'n bepaalde bril opsit om die res van die evangelie op hierdie wyse te lees. Wat hierdie bril is, sal ons verderaan nog moet uitspel. Ulrich Luz is egter volkome reg as hy beweer dat die groot aantal vervullingsitate in die proloog daaraan toe te skryf is dat hier 'der Evangelist diejenigen Gesichtspunkte und Akzente einführt, die für das ganze Evangelium wichtig sind und die der Leser während des ganzen Evangeliums im Auge behalten muss. Die im übrigen Evangelium verstreuten Erfüllungszitate sind dann Erinnerungen daran' (Luz 1985: 140).

Soos ons sitaat in 2:15 word nog 8 ander deur hína of hópōs plus plèrōthe voorafgegaan. Slegs in twee gevalle kry ons bloot 'n tóte (2:17 en 27:9). In albei laasgenoemde gevalle gaan dit om 'n diep-ontstellende gebeure as gevolg van skreiende menslike sonde: In die eerste geval om Herodes se kindermoord en in die tweede geval om die nadraai van Judas se verraad. Dat ons evangelis hína of hópōs hier vermy, is geensins toevallig nie. Die hína/hópōs-inleidings dui immers op die uitvoering van God se heilsbedoeling en heilsplan soos reeds in die Ou Testament geopenbaar (so ook Gundry 1982: 24). Matteus is nie bereid om die kindermoord of Judas se verraad selfs by implikasie op God se rekening te plaas nie. Om dit dogmaties te stel: Die sonde is vir hom nie buite God se wil nie, maar dan tog beslis nie in God se direkte bedoeling nie.

Dit bring ons nou egter terug by die nege hína/hópōs-inleidings. Hierdie inleidings wil sonder twyfel almal beklemtoon dat Jesus se weg nie ' $n$ eiewillige, selfgekose weg was nie, maar die weg wat sy Vader vir Hom bepaal het. En terugskouend van Jesus na die Ou Testament (nie andersom nie) vind Matteus dat hierdie Vader van Jesus Christus, wat niemand anders as die God van die Ou Testament is nie, sy plan reeds in die Ou-Testamentiese geskrifte geopenbaar het. In Matteus 1-2 word hierdie goddelike inisiatief nog verder daardeur beklemtoon dat nie net $2: 15$ nie, maar ook $1: 18-25 ; 2: 1-12$ en $2: 19-23$, naas die Skrifsitaat, 'n goddelike aanwysing deur middel van 'n droom (of 'n ster in een geval) bevat. Hierby kom nou in Matteus 2 'n verdere gesigspunt: Stendahl (1968: VII v) het naamlik gewys op die belang van 
die geografiese verwysings in die sitate in hierdie hoofstuk: Betlehem (vs 6), Egipte (vs 15) en Nasaret (vs 23). (Rama word nie aan Jesus se bewegings verbind nie.) Sy gevolgtrekking is dat die sitate in Matteus 2 'n apologetiese funksie verrig: Hulle moet Jesus se geografiese herkoms verduidelik. France (1981: 237) sluit hierby aan. Volgens hom moet hierdie sitate verduidelik 'how the baby of Bethlehem became the prophet of Nazareth'.

Hierdie standpunt is inderdaad nie sonder meriete nie. Ook 1:1-25 bevat waarskynlik sterk apologetiese tendense.* Ons kan met sekerheid aanvaar dat Matteus as skrywer in noue voeling was met Joodse denke. Dat volgens Christene Jesus Christus, die Seun van Dawid, die Messiaskoning, uit die veragte Nasaret in Galilea afkomstig sou wees en nie uit die roemryke Dawidstad Betlehem nie, het sekerlik baie Jode se wenkbroue laat lig. Die beklemtoning van God se inisiatief in Jesus se bewegings is bedoel om hulle te 'teologiseer'. Die verskuiwing van Betlehem via Egipte na Nasaret was, so beklemtoon Matteus, 'n noodsaaklike deel van God se weg met sy Messias.

Matteus se hantering van sy vervullingsitate word nog merkwaardiger as ons kyk na die twee sitate waarin hy, anders as in die ander nege, die Kurios (Jahwe) direk aan die woord stel. Hierdie twee plekke is $1: 23$ en ons sitaat in 2:15. In al die ander gevalle geskied die uitspraak bloot 'deur' (dia) 'n profeet of profete. ${ }^{* *}$ Die rede waarom God hier so prominent aan die woord kom, lê ook nie daarin dat Jahwe in die betrokke Ou-Testamentiese passasie self die direkte spreker is nie. Ander sitate wat aan hierdie selfde vereiste voldoen, word nie as Jahwespreuk beklemtoon nie.** Die oplossing lê eerder in die belangrikheid van die inhoud van hierdie twee uitsprake: In albei gevalle gaan dit om 'n ontsluiting van Jesus se identiteit, met ander woorde om die beantwoording van die vraag: 'Wie is hierdie Jesus?' Hierdie is so 'n belangrike en geheimenisvolle saak dat God Hom self moet be-

* Dit is heel moontlik dat reeds die verwysings na vroue met 'n slegte reputasie in die geslagsregister, asook die groot klem op Josef se verleentheid en Jesus se ontvangenis uit die Heilige Gees, ' $n$ apologetiese of straks selfs polemiese strekking het in die lig van Joodse belasteringe dat Jesus die kind van Maria by ' $n$ Romeinse soldaat sou wees. Vir die skriftelike neerslag hiervan in rabbynse bronne, kyk Strack-Billerbeck (I 1956: $36 \mathrm{vv})$.

** 'n Mens sou kon vra of rhēthēn nie 'n passivum divinum is en God dus in elk geval ook in hierdie ander tekste as die auctor primarius veronderstel word nie. Dit mag wel so wees, maar dan is die eksplisiete vermelding van die heilige Kuriosnaam in hierdie twee gevalle - en daarby nog in die heel eerste twee vervullingsitate in Matteus - des te opvallender; dan dra hulle nog soveel meer gewig. 
kendstel. Dit is God self wat moet verklaar dat Jesus nie net die Seun van Dawid (vs 1, 6, 17), die Seun van Abraham (vs 1, 17), ja die Christus (vs 16,17$)$ is nie, maar ook die Seun van God en die Immanuel. Matteus 2:15 vorm dus ' $n$ uiters belangrike skakel in die ketting van uitsprake waarin Jesus steeds duideliker as Seun van God bekendgestel word. Sy Seunskap word verhuld gestel in 1:16 waar die ex hès egennèthe impliseer dat God Jesus se Vader is. (Hierdie uitspraak handel nie oor Jesus se geboorte nie, maar oor sy verwekking deur God - vgl Pesch 1967:417 v.) Hierdie selfde motief word in die daaropvolgende vertelling aangaande Josef se verleentheid en Jesus se verwekking uit 'n maagd deur die werking van die Heilige Gees verder uitgebou (vgl o a hoe gennethén (vs 20) by vs 16 aansluit). Hierdie geïmpliseerde Seunskap word in die sitaat 1:23 voortgesit, alhoewel die klem sterker op die Immanuelmotief val. In 2:15 noem God Jesus vir die eerste keer in soveel woorde sy Seun, maar sy Seunskap staan nog nie ten volle in die fokus nie. In die doopperikoop is dit egter voluit die geval: 'Dit is my geliefde Seun in wie Ek My verheug' (3:17; vgl ook hoe Jesus in die daaropvolgende versoekings aangespreek word $(4: 3,6))$. Ons hoef hierdie lyn nie nou verder deur te trek nie. Dit is egter wel belangrik om raak te sien dat daar ' $n$ hele stuk teologie skuil agter die wyse waarop Matteus sy sitaat aanbied. Wanneer Petrus in 16:16 bely dat Jesus 'die Christus, die Seun van die lewende God' is, verklaar Jesus dat dit nie vlees en bloed is wat dit aan Hom geopenbaar het nie, maar 'my Vader wat in die hemel is' (vs 17). God kan slegs deur God geken word, en deur diegene aan wie Hy Hom openbaar (Pesch 1967: 416). En dit is wat hier in 1:23 en 2:15 plaasvind (vgl die stem uit die hemel in 3:17, asook 11:27 en 17:5).

Ons vat saam: Binne Matteus se eie konteks wil die aanhaling in 2:15 die volgende beklemtoon:

1. Dat Jesus se lewensweg, ook sy verblyf en uitroep...g uit Egipte, nie maar lukraak of 'n stuk menslike eiewilligheid was nie, maar die deur God gewilde en beplande weg vir die Messiaskoning, die Immanuel, die Seun van God.

2. Dat hierdie pad vanaf die Dawidstad juis via Egipte na die veragte Nasaret in Galilea moes gaan. Gebruikmaking van die Ou Testament staan hier in diens van die vroeg-Christelike apologie. France (1981: $238 \mathrm{v}$ ) en Luz (1985: 129) meen albei dat die nie-Joodse plekname in Matteus 2 (Ooste, Egipte, Nasaret) bedoel is om klem te laat val op die universele skopus van Jesus se taak: Die tekste gee ons egter geen aanduiding hiervan nie. Hierdie faset word wel in 4:14-16, en dan ook baie prominent, aan die orde gestel. 
3. Dat bogenoemde reeds deur God in die Ou-Testamentiese geskrifte geopenbaar is en dat hierdie 'vooruitskouing' in Jesus Christus vervul is.

4. Dat Jesus inderdaad nie net Seun van Dawid, die Messiaskoning (Koning van die Jode) is nie, maar ook Seun van God. Hy is dus in die volsin van die woord God met ons: Immanuel. Hierdie geheimenis is so groot en so belangrik dat die Here self, en Hy alleen, dit aan mensekinders openbaar.

\section{MATTEUS SE GEBRUIKMAKING VAN HOSEA 11:1}

Dit is duidelik dat ons nie, soos Matteus gedoen het, die gebeure van Matteus 2:15 in Hosea 11:1 mag teruglees of Hosea 11:1 in Matteus 2:15 mag inlees nie. Elke uitspraak moet in sy eie konteks geëksegetiseer word. Dit los egter nog nie ons probleemstelling aan die begin op nie. Daarom moet ons nou daarheen terugkeer.

Ons moet aanvaar dat Matteus in sy gebruikmaking van Ou-Testamentiese aanhalings die uitlegmetodes van sy tyd volg. Hiervolgens is die Ou Testament dikwels op sy bewoording af en sonder inagneming van eie konteks op die hede toegepas. Hiervan het ons in die Qumrangeskrifte talle voorbeelde. Die grondliggende gedagte is dat die betrokke Ou-Testamentiese teks met die oog op die hede geskryf is, of ten minste, afgesien van wat vir hulle eie tyd bedoel was, ' $n$ meerwaarde vir die hede het. In hierdie gees gaan iemand soos Matteus nie van die Ou Testament na Christus nie, maar vanuit sy oorweldigende Christusbelewenis en dié van sy kerk terug na die Ou Testament en lees dit met 'n Christusbril. Op hierdie wyse ontdek hy Christus telkens in die Ou Testament. Dat hierdie Christusgerigtheid van OuTestamentiese tekste volgens Matteus ook in die Ou-Testamentiese skrywer se eie bedoeling geleë was, blyk uit 'n gedeelte soos Matteus 3:3 waar die evangelis 'n uitspraak uit Jesaja 40:3 op Johannes die Doper toepas en in sy inleiding tot hierdie uitspraak sê: 'Dit is hy wat deur Jesaja die profeet bedoel is toe hy gesê het...' (Légō beteken in die Nuwe Testament meermale 'bedoel'.)

Ons sal in ons eie eksegetiese metodiek nie Matteus se metode kan volg nie. Ons sal nie saam met hom in Hosea 11:1 'n direkte heenwysing na Christus kan vind nie. Ek verstout my om te sê dat daar vandag ook geen erkende Ou-Testamentiese wetenskaplike sal wees wat dit sal doen nie. Ons gelowige waardering vir die boodskap van Matteus 2:15 lê inderdaad op 'n ander vlak: Op die vlak van sy geloofsgetuienis binne sy eie konteks. 
Tog bly daar ten slotte nog een belangrike vraag oor wat ons moet probeer beantwoord ('n vraag wat ook by ander Ou-Testamentiese aanhalings in die Nuwe Testament gestel moet word): Die vraag of daar nie, indien dan nie 'n regverdiging nie, dan tog wel 'n saaklike verklaring of verduideliking vir die sitering van Hosea 11:1 in Matteus 2:15 bestaan. Dit lyk my wel die geval te wees. Ons het naamlik gesien hoe Matteus self die parallel tussen Israel en Christus trek. Die Immanuel, die Koning van die Jode, vereenselwig Hom volkome met die Godsvolk. Hulle lot word sy lot. Wat met hulle gebeur, gebeur met Hom. Ons kan toegespits sê: $\mathrm{Hy}$ is Israel; die eindpunt van die ou Israel en die beginpunt van die nuwe, ware Israel van die Nuwe Testament. Vanuit sy eie teologie, is dit begryplik dat Matteus 'n uitspraak wat op Israel gerig was, Christologies kan benut.

Hierby kom nog 'n ander gesigspunt: Waar God met sy mense besig is, daar loop sekere tipiese tendense deur die geskiedenis en kan die geskiedenis homself herhaal en profetiese uitsprake meer as een vervulling hê. Hierdie besef het ook in Israel se teologiese denke neerslag gevind. Ons vind veral in die vroeë Jodedom se eskatologiese verwagting die tendens dat byvoorbeeld elemente uit die Eksodusgebeure hulle in die Messiaanse tyd sou herhaal. Strack-Billerbeck (I 1956: $85 \mathrm{v}$ v) wys op die verwagting dat die Messiaanse verlosser uit Egipte sou kom. Sluit Matteus moontlik hierby aan? Ons het nie voorbeelde waar Hosea 11:1 in hierdie verband benut word nie. Tog lê daar dikwels tussen 'n Ou-Testamentiese teks soos ons dit in die Hebreeus het en die Nuwe-Testamentiese tekste 'n lang stuk Wirkungsgeschichte waarvan ons spore in die Septuagint en vroeg-Joodse bronne kan vind. En dieselfde soort Wirkungsgeschichte vind ons in die vroeë kerk.

Van die Jodedom se teologiese verwerking van die geskiedenis en die daarmee saamhangende Wirkungsgeschichte van Ou-Testamentiese tekste weet en verstaan ons in baie gevalle nog nie genoeg nie. Meerdere kennis en insig hierin sou ons in meer as een geval kon help om te verstaan hoe 'n skrywer by 'n bepaalde sitaat uitgekom het.

\section{TEN BESLUITE:}

Ek het aan die begin gewaarsku teen die gevaar van veralgemenings. Ek moet die waarskuwing hier aan die einde herhaal. Wat hierbo gesê is, geld vir Matteus 2:15 en sekerlik ook vir baie ander Ou-Testamentiese aanhalings in die Nuwe Testament. Daar is egter ook aanhalings wat op 'n ander vlak lê en wat tot ander insigte sal lei. Nietemin lyk dit 
vir my of die ondersoek na saaklike verbande en die beter verstaan van Israel en die vroeë Jodedom se teologiese verwerking van die geskiedenis, soos onder meer blyk uit die wyse waarop Ou-Testamentiese tekste ontvang en hanteer is, interessante en vrugbare toekomsmoontlikhede vir die beter verstaan van $\mathrm{Ou}$-Testamentiese sitate in die Nuwe Testament inhou.

Twee basiese dinge is in hierdie verband duidelik: Eerstens dat ons as Christene nie die Ou Testament kan lees asof Christus wel nooit gekom het nie. Daarom kyk ons vanuit Christus met ander oë na die Ou Testament as die Jood. En tweedens dat Christus in die Ou Testament teenwoordig is. Al sou daar verskil wees oor die hoe van sy teenwoordigheid, oor die dat deel ons Matteus en die Nuwe-Testamentiese skrywers se standpunt. Die God van die Ou Testament is immers geen ander God as dié van die Nuwe Testament nie.

Grundmann (1968: 71) herinner in hierdie verband aan Jesus se woorde volgens Matteus 13:52 oor die 'skrifgeleerde wat 'n leerling word in die koninkryk van die hemel' en wat is 'soos 'n huiseienaar wat uit sy voorraad nuwe en ou dinge te voorskyn bring'. Hierdie woord is sekerlik van toepassing op Matteus, en dit is selfs moontlik dat hy self sy arbeid as evangelis hierby betrek het. Die volgorde is belangrik: Eers die nuwe dinge, dan die oue; vanuit die evangelie terug na die Ou Testament. Maar sy woorde staan in die Bybel ook as 'n uitnodiging aan ons om sy Anliegen voort te sit en om, soos hy, skrifgeleerd in die Koninkryk te word en so, volgens die lig wat aan ons gegee word, eerlik te worstel met die vraag van die Christusverkondiging van die Ou Testament.

\section{Literatuurverwysings}

COMBRINK, HJB 1985. Die Evangelie volgens Matteus: Inleiding en teologie, in Du Toit, AB (red), Die Sinoptiese Evangelies en Handelinge: Inleiding en teologie, 59-105. Pretoria: NG Kerkboekhandel (Handleiding by die Nuwe Testament iv.)

FRANCE, RT 1981. The formula-quotations of Matthew 2 and the problem of communication. NTS 27, 233-251.

GRUNDMANN, W 1968. Das Evangelium nach Matthäus. Berlin: Evangelische Verlagsanstalt. (ThHKI.)

GUNDRY, RH 1982. Matthew: A commentary on his literary and theological art. Grand Rapids: Eerdmans.

LUZ, U 1985. Das Evangelium nach Matthäus (Mt 1-7). Zürich: Benziger Verlag. (EKK.)

PESCH, R 1967. Der Gottessohn im matthäischen Evangelienprolog (Mt 1-2). Biblica 48, 395-420.

PRINSLOO, WS 1986. 'Aanhalings' van die Ou Testament deur die Nuwe Testament: Hosea 11:1/Matteus 2:15. HTS 42, 378-385. 
ROTFUCHS, W 1969. Die Erfüllungszitate des Matthäus-Evangeliums. Stuttgart: Kohlhammer. (BWANT 5. Folge 8.)

STENDAHL, K 1968. The school of St Matthew. 2nd ed. Philadelphia: Fortress.

STRACK, HL \& BILLERBECK, P 1956. Kommentar zum Neuen Testament aus Talmud und Midrasch. Erster (Doppel-) Band: Das Evangelium nach Matthäus. 2 Auflage. München: Beck.

THOLUCK, A 1838 (red). Ioannis Calvini in Novum Testamentum commentarii I: Harmoniae Evangeliorum, p I. 2. editio. Berolini: Guilelmus Thome.

VAN AARDE, AG 1982. God met ons: Dié teologiese perspektief van die Matteusevangelie. DD-proefskrif, Universiteit van Pretoria. 